\title{
Electronic and Electrical Engineering
}




\section{Other Macmillan titles of related interest:}

W. A. Atherton, From Compass to Computer

B. R. Bannister and D.G. Whitehead, Fundamentals of Modern Digital Systems

J. C. Cluley, Transistors for Microprocessor Systems

Donard de Cogan, Solid State Devices - A Quantum Physics Approach

C. W. Davidson, Transmission Lines for Communications, second edition

M. E. Goodge, Analog Electronics

B. A. Gregory, An Introduction to Electrical Instrumentation and Measurement Systems, second edition

Paul A. Lynn, An Introduction to the Analysis and Processing of Signals, third edition

Noel M. Morris, Electrical Circuit Analysis and Design

P. Silvester, Electric Circuits

L. A. A. Warnes, Electronic Materials

B. W. Williams, Power Electronics - Devices, Drivers, Applications and Passive Components

\section{Macmillan New Electronics Series}

Series Editor: Paul A. Lynn

Rodney F. W. Coates, Underwater Acoustic Systems

M. D. Edwards, Automatic Logic Synthesis Techniques for Digital Systems

Peter J. Fish, Electronic Noise and Low Noise Design

W. Forsythe and R. M. Goodall, Digital Control

C. G. Guy, Data Communications for Engineers

Paul A. Lynn, Digital Signals, Processors and Noise

Paul A. Lynn, Radar Systems

R. C. V. Macario, Cellular Radio - Principles and Design

A. F. Murray and H. M. Reekie, Integrated Circuit Design

F. J. Owens, Signal Processing of Speech

Dennis N. Pim, Television and Teletext

M. Richharia, Satellite Communications Systems

M. J. N. Sibley, Optical Communications

P. M. Taylor, Robotic Control

G. S. Virk, Digital Computer Control Systems

Allan Waters, Active Filter Design 


\title{
Electronic and Electrical Engineering
}

\section{Principles and Practice}

\author{
L. A. A. Warnes
}

Department of Electronic and Electrical Engineering

Loughborough University of Technology

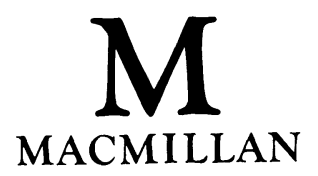


다 L. A. A. Warnes 1994

All rights reserved. No reproduction, copy or transmission of this publication may be made without written permission.

No paragraph of this publication may be reproduced, copied or transmitted save with written permission or in accordance with the provisions of the Copyright, Designs and Patents Act 1988, or under the terms of any licence permitting limited copying issued by the Copyright Licensing Agency, 90 Tottenham Court Road, London W1P 9HE.

Any person who does any unauthorised act in relation to this publication may be liable to criminal prosecution and civil claims for damages.

Dedicated to Alexis Warnes

First published 1994 by THE MACMILLAN PRESS LTD

Houndmills, Basingstoke, Hampshire RG21 2XS and London

Companies and representatives

throughout the world

ISBN 978-0-333-58000-4 ISBN 978-1-349-13012-2 (eBook)

DOI 10.1007/978-1-349-13012-2

A catalogue record for this book is available from the British Library

Cover photographs courtesy of Intel Corporation (UK) Ltd and Barnaby's Picture Library (London) 


\section{Contents}

Preface

Constants

Units

1 Circuit analysis

1.1 Sources

1.2 Passive circuit elements

1.3 Practical circuit elements

1.4 Circuit analysis and Kirchhoff's laws

1.5 Circuit theorems and transformations

1.6 Power and energy

1.7 Mesh analysis and nodal analysis

2 Sinusoidally-excited circuits

2.1 Sinusoidal excitation

2.2 Phasors

2.3 Circuit analysis with AC

2.4 Power in AC circuits

2.5 Resonant circuits

3 Operational amplifiers

3.1 The golden rules

3.2 Some common op-amp circuits

3.3 Analogue computing

3.4 Practical op amps

3.5 Comparators

3.6 Schmitt triggers

4 Transients

4.1 Transients in RC and RL circuits 83

4.2 The Laplace transformation 89

4.3 Transients in RLC circuits 101

5 Bode diagrams and twoport networks

5.1 The steady-state frequency response of circuits

5.2 Two-port networks

83
6 Semiconductors

128

6.1 Electrons and holes in semiconductors

128

6.2 Electrical conductivity

129

6.3 The p-n junction

132

6.4 A glossary of terms

133

7 Diodes

136

7.1 Junction diodes 136

7.2 Schottky diodes $\quad 140$

7.3 Zener diodes 142

7.4 Light-emitting diodes (LEDs) 145

7.5 Applications for diodes 147

8 Bipolar junction transistors 156

8.1 Theory of operation

156

8.2 Characteristics of the commonemitter amplifier

158

8.3 Biasing the transistor:

Q-point and load lines

8.4 The small-signal equivalent circuit

8.5 The voltage-divider bias circuit

8.6 The $h$-parameters

162

164

8.7 The low-frequency response 166

8.8 The high-frequency response 166

8.9 The emitter follower, or common-collector amplifier $\quad 168$

8.10 Transistor switches $\quad 170$

8.11 BJT specifications $\quad 171$

9 Field-effect transistors

175

9.1 The structure of a FET

9.2 The junction field-effect transistor

175

9.3 The practical FET amplifier

9.4 Specifications of some readily available FETS

176

179

182

10 ICs and analogue circuits 185

10.1 IC fabrication technology

186 
10.2 Analogue circuits

10.3 Filters

10.4 Oscillators

10.5 Voltage regulators

10.6 Analogue-to-digital and digitalto-analogue converters

\section{Power amplifiers and power supplies}

11.1 Class-A amplifiers

11.2 Class-B amplifiers

11.3 Class-C amplifiers

11.4 Class-D amplifiers

11.5 Power supplies

11.6 Cooling

\section{Magnetism and electro- magnetism}

12.1 Magnetic units and quantities

12.2 The magnetic circuit

12.3 Hysteresis

12.4 Eddy currents

12.5 Faraday's law of electromagnetic induction

12.6 Inductors

\section{DC machines}

13.1 A prototype machine

13.2 DC generators

13.3 DC motors

13.4 Efficiency and losses

14 Three-phase systems

14.1 The generation of three-phase electricity

14.2 Balanced loads

14.3 Unbalanced loads

14.4 Power measurement in threephase circuits

211

211

215

218

219

220

223

227

227

229

230

233

233

237

239

239

242

252

262

267

267

270

272

276

15 Transformers

279

15.1 The ideal transformer

279

15.2 The equivalent circuit of a transformer

15.3 Calculating leakage inductance

90

190

04

205

199

1

1

5

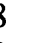

3

7


19.4 de Morgan's theorems

362

19.5 Negative logic

363

19.6 Minterms and maxterms

19.7 Karnaugh mapping and circuit minimisation

19.8 Some practical examples

370

19.9 Programmable logic arrays

374

19.10 Practical aspects of logic circuits 375

\section{Sequential logic}

20.1 Unclocked flip-flops

378

20.2 Clocked flip-flops

380

20.3 Counters and shift registers

382

20.4 The monostable multivibrator

389

20.5 Timers

390

20.6 Multiplexers

391

\section{Computers}

21.1 Computer architecture

21.2 The CPU

21.3 Memory

21.4 Input and output devices

21.5 Computer networks

21.6 Programming languages

\section{Microprocessors and microcontrollers}

22.1 The Intel MCS-51 microcontrollers

22.2 The 8051 clock and the machine cycle time

22.3 The special-function registers

424

22.4 Moving data

432

435

438

22.6 Arithmetic operations

22.7 Jumps

22.8 Calls and subroutines

22.9 Look-up tables

\section{Analogue communications}

23.1 The elements of a communications system

23.2 The electromagnetic spectrum

23.3 Amplitude modulation

23.4 Frequency modulation

23.5 AM and FM compared

23.6 Pulse modulation

445

446

448
23.7 Noise

463

24 Digital communications

476

24.1 Binary modulation

476

24.2 Pulse-code modulation

483

24.3 The theoretical maximum for the channel capacity

488

25 Fibre-optic communications

491

25.1 Pros and cons of fibre-optics 491

25.2 The transmitter

492

25.3 The channel: optical fibres

494

25.4 Optoelectronic signal detectors 501

25.5 The ultimate performance of optical receivers

504

26 Telephony

507

26.1 Signalling

507

26.2 BORSCHT 509

26.3 Transmission systems $\quad 509$

26.4 Multiplexing 511

26.5 Companding 512

26.6 Telephone exchanges 513

26.7 Telephone-traffic theory 515

26.8 SPC exchanges $\quad 518$

26.9 The integrated services digital network (ISDN)

520

27 Electromagnetic compatibility

522

27.1 Sources of EMI 523

27.2 Conductor shielding $\quad 524$

27.3 Grounding 527

27.4 Shielding with sheet conductors 529

27.5 EMI filtering 533

27.6 Legal requirements: EN55014 537

\section{Measurements and} instruments

540

28.1 Accuracy

540

28.2 Standards and transducers for measurements

543

28.3 Instruments

546 


\section{Preface}

A

N UNDERSTANDING of the basic principles and many of the important practical applications of electronic and electrical engineering is now essential to many practitioners of other disciplines. Through teaching electrical engineering subjects to electrical, civil, mechanical and production engineering students over a number of years, I have been aware that there is an urgent need for a book which goes into sufficient depth to be useful, without being over-complicated or cluttered with toorigorous and exhaustive a mathematical treatment. In this book, the level of mathematical difficulty is approximately that of A-level, though in most chapters there is nothing so advanced. The aim here has been to establish the foundations thoroughly and then build onto them at least the ground floor of the edifice that this vast subject has evolved into today. While the requirements of the non-specialist are given due priority, the intention is also to provide a useful first course for $\mathrm{HNC} / \mathrm{HND}$ and undergraduate engineering students. I hope that the practical side of the subject has not been lost to sight; and it has been my intention throughout to illustrate the theory with applications, wherever possible.

The book starts with two chapters on the fundamental subject of circuit analysis, or circuit theory. These are succeeded by chapters devoted to operational amplifiers and the steady-state and transient responses of circuits. Semiconductor theory is briefly reviewed in chapter 6, following which discrete devices and circuits are discussed in chapters 7,8 and 9. Chapter 10 deals with integrated circuits and the more common analogue circuits. Machines and power make up an important central section of the work in Chapters 11 to 18. Digital electronics, computers and microprocessors are discussed in Chapters 19 to 22 . There are four chapters given to communications, including analogue, digital and fibreoptic communications and telephony. Two concluding chapters deal with less central subjects of considerable importance to a wide public: electromagnetic compatibility (EMC) and instruments and measurements. EMC has become far more important since wideranging EC regulations became law and now affects every single piece of electrical equipment made and used in the Community. A working knowledge of electrical measurements, their accuracy and achievement is essential to engineers and technicians in every field, and a chapter on these topics rounds off the book.

Many people have helped in writing this book, especially the reviewers, of which there have been a score or more, known and unknown. I am also grateful to my students who have from time to time taken the trouble to read parts of the work and have offered useful suggestions for improvement: Wayne Lyons in particular was very helpful with microcontrollers. My thanks to all of these, but a special word of gratitude to my publisher, Malcolm Stewart, who has maintained a keen interest in the genesis and sometimes difficult birth of this offspring and has never been less than encouraging. To my wife, Irene, I offer my apologies for taking up the pen so very soon after I had said I would not, with all the consequent sacrifices of time and attention; and my thanks too for her unfailing support and encouragement.

Loughborough, 1993

L.A.A.W. 


\section{Constants}

The speed of light in a vacuum, $c$

The permeability of free space or the magnetic constant, $\mu_{0}$ The permittivity of free space or the electric constant, $\varepsilon_{0}$ Planck's constant, $h$ Boltzmann's constant, $k$ The electronic charge, $q$
$3 \times 10^{8} \mathrm{~m} / \mathrm{s}$

$4 \pi \times 10^{-7} \mathrm{H} / \mathrm{m}$

$8.85 \times 10^{-12} \mathrm{~F} / \mathrm{m}$

$6.626 \times 10^{-34} \mathrm{Js}$

$1.38 \times 10^{-23} \mathrm{~J} / \mathrm{K}$

$1.6 \times 10^{-19} \mathrm{C}$

Notes: $c=1 / \sqrt{ }\left(\mu_{0} \varepsilon_{0}\right)$. Impedance of free space, $Z_{0}=\sqrt{ }\left(\mu_{0} / \varepsilon_{0}\right)=377 \Omega$. The above, where approximated, are accurate to $\pm 0.14 \%$. 


\section{Units}

Base units

\begin{tabular}{llll}
\hline Quantity & Unit & Symbol & Dimension \\
\hline & & & \\
Mass & kilogram & $\mathrm{kg}$ & $\mathrm{M}$ \\
Length & metre & $\mathrm{m}$ & $\mathrm{L}$ \\
Time & second & $\mathrm{s}$ & $\mathrm{T}$ \\
Current & ampere & $\mathrm{A}$ & $\mathrm{I}$ \\
Temperature & kelvin & $\mathrm{K}$ & $\boldsymbol{\theta}$ \\
\hline
\end{tabular}

\section{Derived units}

\begin{tabular}{llll}
\hline Quantity & Unit & Symbol & Dimensions \\
\hline & & & \\
frequency & hertz & $\mathrm{Hz}$ & $\mathrm{T}$ \\
speed & metre/second & $\mathrm{m} / \mathrm{s}$ & $\mathrm{LT}^{-1}$ \\
acceleration & metre/sec/sec & $\mathrm{m} / \mathrm{s}^{2}$ & $\mathrm{LT}^{-2}$ \\
force & newton & $\mathrm{N}$ & $\mathrm{MLT}^{-2}$ \\
work, energy & joule & $\mathrm{J}$ & $\mathrm{ML}^{2} \mathrm{~T}^{-2}$ \\
power & watt & $\mathrm{W}$ & $\mathrm{ML}^{2} \mathrm{~T}^{-3}$ \\
charge & coulomb & $\mathrm{C}$ & $\mathrm{TI}^{2}$ \\
potential & volt & $\mathrm{V}$ & $\mathrm{ML}^{2} \mathrm{~T}^{-3} \mathrm{I}^{-1}$ \\
resistance & ohm & $\Omega$ & $\mathrm{ML}^{2} \mathrm{~T}^{-3} \mathrm{I}^{-2}$ \\
conductance & siemens & $\mathrm{S}$ & $\mathrm{M}^{-1} \mathrm{~L}^{-2} \mathrm{~T}^{3} \mathrm{I}^{2}$ \\
capacitance & farad & $\mathrm{F}$ & $\mathrm{M}^{-1} \mathrm{~L}^{-2} \mathrm{~T}^{4} \mathrm{I}^{2}$ \\
inductance & henry & $\mathrm{H}$ & $\mathrm{ML}^{2} \mathrm{~T}^{-2} \mathrm{I}^{-2}$ \\
$\begin{array}{l}\text { magnetic field } \\
\text { flux density }\end{array}$ & ampere/metre & $\mathrm{A} / \mathrm{m}$ & $\mathrm{L}^{-1} \mathrm{I}^{-2}$ \\
magnetic flux & tesla & $\mathrm{T}$ & $\mathrm{MT}^{-2} \mathrm{I}^{-1}$ \\
& weber & $\mathrm{Wb}$ & $\mathrm{ML}^{2} \mathrm{~T}^{-2} \mathrm{I}^{-1}$ \\
\hline
\end{tabular}

